\title{
Designing Four Notched Bands Microstrip Antenna for UWB Applications, Assessed by Analytic Hierarchy Process Method
}

\author{
Y. Zehforoosh ,M. Mohammadifar, \\ Department of Electrical Engineering, Urmia Branch, Islamic Azad University, Urmia, Iran \\ Y.zehforoosh@srbiau.ac.ir, Mohammadifar_eng@yahoo.com,
}

Amir houshang Mohammadifar, Seyedeh Roghaye Ebadzadeh Sama Technical and Vocational Training College, Khoy Branch, Islamic Azad University, Khoy, Iran. Department of Electrical Engineering, Urmia Branch, Islamic Azad University, Urmia, Iran Mohammadifar_mec@yahoo.com,_Roghaye.ebadzadeh@gmail.com

\begin{abstract}
In this study, a novel microstrip fed Ultra Wideband (UWB) antenna is presented. The proposed antenna, with a size of $26 \times 30 \times 1.6 \mathrm{~mm}^{3}$, is capable of removing four bands of interference in the coverage band. Firs, three filtered bands are created by cutting U, L, and C-shapes, a horizontal line on the patch, and fed line of antenna. The fourth notch is created by a new method that involves the use of a metalized via-hole and a C-shaped strip line in the rear side of the radiation patch. In the next step, the proposed antenna is compared with similar models with regard to different features such as size, bandwidth, and the number of the filtered frequency bands, in a new framework based on the Analytic Hierarchy Process. Thus, with a comprehensive comparison, the functional aspects of the proposed antenna are presented. The characteristics of the proposed antenna, such as radiation pattern, gain, and return loss $\left(\mathrm{S}_{11}<-10 \mathrm{~dB}\right)$, were measured; the correspondence between the simulated and measured results was acceptable.
\end{abstract}

Index Terms - Analytical hierarchy Process, ultra-wideband antenna, Lshaped slot antenna, U-shaped slot antenna

\section{INTRODUCTION}

Recently, researchers developed ultra-wideband (UWB) systems with the aim of achieveing wider operating bandwidth, high speed data, lower power spectrum, etc. [1]. The restriction of UWB frequency spectrum (from 3.1 to $10.6 \mathrm{GHz}$ ) by Federal Communications Commission (FCC), directed researchers' attention toward using UWB communication systems, and many monopole antennas with different patches or slots were considered for UWB systems [1]. Nevertheless, the design of UWB systems is still facing many challenges [2]. For rinstance, in case of covering wider bandwidth, UWB systems could easily be interfered with the adjacent systems such as the wireless local area networks (WLANs) operating in the IEEE WiMAX network 3.35-GHz (3.3-3.4 GHz), 3.5-GHz (3.4-3.6 GHz), 3.7-GHz (3.6-3.8 GHz) (5.725-5.85 GHz), WLAN 5.25-GHz $(5.15-5.35 \mathrm{GHz})$ and $5.75-\mathrm{GHz}$ (5.725-5.825 GHz), IEEE INSAT/Super-Extended C-band, and X-band 7.5-8.5 GHz operating bands. Many systems and companies can be allowed to adjust operation to, at least, one or more of these 
bands [3]. Therefore, the UWB systems are always at risk of being affected by several interference signals. A simple method to solve the mentioned problem is designing the UWB antennas with bandnotched characteristics to conquer the interference signals. Hitherto, many works have been reported to apply different methods in order to achieve band notched characteristics. Etching slots on the UWB antenna radiator are among the earliest methods wildely discussed so far. For example, some UWB antennas with band rejected characteristics have been realized using a U-slot [4-7], an L-slot [8-9], a rectangular slot [10], a V-slot [11], an H-slot [12], and an E-slot [13]. Other methods often employed in this regard include implementation of parasitic element structure [14], folded strips [15], split-ring resonators (SRRs) [16], meander-ground structures [17-18], resonated cells on the coplanarwaveguide (CPW) [19], fractal tuning stub [20], slots on the ground [21], slots or folded-strip lines along the antenna feed line [22- 23], and quarter-wavelength tuning stubs [24]. Most of these references focused on designing antennas with one notch characteristic expected for [18]. However, some papers with multiple notches are reported in [25-27]. In this paper, with a novel approach of combining the mentioned methods, a four notched ultra wideband antenna is presented. The most important future of the proposed antenna in comparison to other antennas presented in literature is the utilization of a parasitic C-shape structure connected with a metalized via hole to attain fourth notch characteristics without any variation in antenna structure.

To evaluate the performance of the proposed UWB antenna compared with other antennas designed previously, the researchers suggested a frame based on Analytical Hierarchy Process (AHP) method. AHP is a method of decision-making where the selection of an antenna from among the previously designed antennas or prioritizing them is based on several effective factors. To apply the AHP method, the study employed the Expert Choice software. In the following sections, detailed explanations regarding the antenna structure and the method of comparison are presented.

\section{ANTENNA STRUCTURE}

The geometry of the proposed four-notched band UWB antenna is demonstrated in Figure 1. The total size of the proposed antenna is $1.24 \lambda \mathrm{g} \times 1.44 \lambda \mathrm{g}\left(26 \times 30 \mathrm{~mm}^{2}\right)$ and it is printed on commercial FR4 epoxy substrate with relative permittivity of $(\varepsilon r=) 4.4$, loss tangent of $(\tan \delta=) 0.02$, and the substrate thickness of $(0.08 \lambda \mathrm{g}) 1.6 \mathrm{~mm}$. To attain $50 \Omega$ input impedance, the researchers used a microstrip feed line with width of $(\mathrm{Wf}=) 3 \mathrm{~mm}$. In rear side of antenna, the ground is formed by a trapezoid shape, the two corners of which are modified to better distribute the current flow. Additionally, to increase the distance between the patch and ground of the antenna, the researchers used a rectangular slit (We $\times$ Le) at the end of the ground which controlled low frequency bandwidth. Microstrip feed line continues to a simple rectangular patch $(\mathrm{Wp} \times \mathrm{Lp})$. The researchers used a stepped triangular where the microstrip feed line and patch meet to attain better distribution of current flow. The values of other dimensions of the proposed antenna are: $\left(\mathrm{L}_{\mathrm{f}}=13, \mathrm{~L}_{\mathrm{g}}=12.5, \mathrm{~L}_{\mathrm{L} 1}=11.6, \mathrm{~L}_{\mathrm{L} 2}=4.785, \mathrm{~L}_{\mathrm{u}}=7, \mathrm{~L}_{\mathrm{c} 1}=4.14\right.$, $\mathrm{L}_{\mathrm{c} 2}=1.96, \mathrm{~L}_{\mathrm{h}}=15.4, \mathrm{~L}_{\mathrm{n}}=12.4, \mathrm{~L}_{\mathrm{p}}=14, \mathrm{~L}_{\mathrm{e}}=4, \mathrm{~W}_{\mathrm{f}}=3, \mathrm{~W}_{\mathrm{u}}=0.9, \mathrm{~W}_{\mathrm{h}}=0.6, \mathrm{~W}_{\mathrm{L}}=1.2, \mathrm{~W}_{\mathrm{c}}=0.33, \mathrm{~W}_{\mathrm{e}}=1, \mathrm{~W}_{\mathrm{p}}=16$, $\mathrm{g}=1.14, \mathrm{~s}=0.5$ and $\mathrm{R}=3$ (all values are in $\mathrm{mm}$ ). 


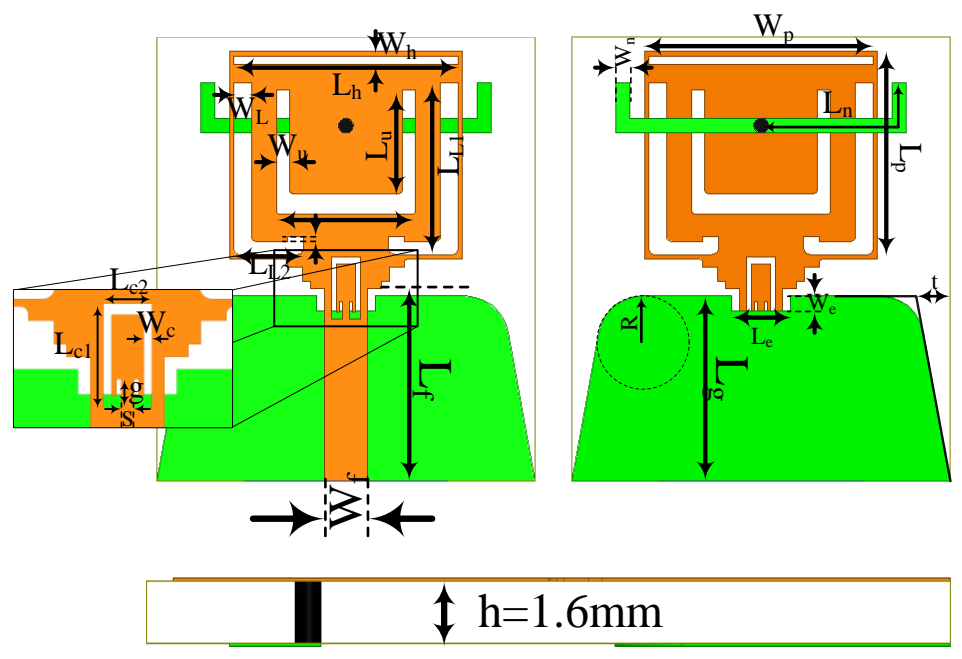

Fig. 1. Configuration of the proposed antenna

A C-shaped slot is etched on microstrip feed line; there are four slots on the patch. A U-shaped slot and a horizontal line are created in the center and at the end of patch, respectively. To keep symmetry of the antenna, the researchers used two L-shaped slots in two sides of the antenna patch. At the other side of substrate, under patch, a C-shape structure which is connected to patch by a metalized via hole is created. The effects of each structure are discussed in the following section.
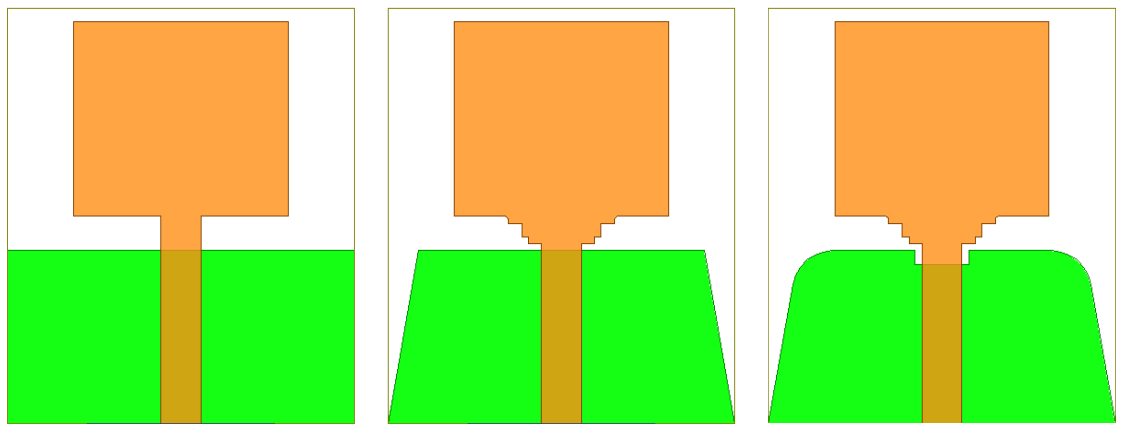

Fig. 2. Three steps of designing proposed UWB antenna; a) step 1, b) step 2, and c) step 3.

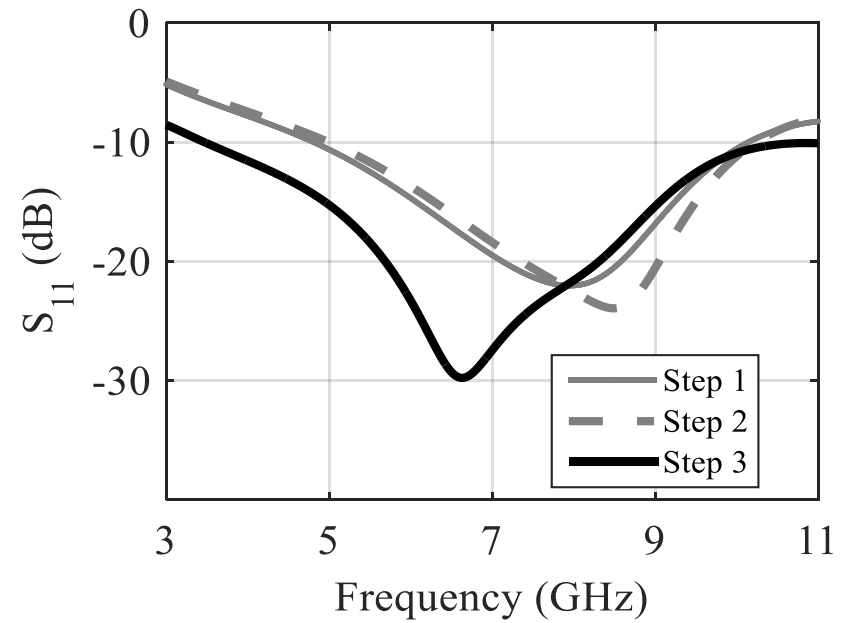

Fig. 3. Simulated results of three step designing of proposed UWB antenna at Fig. 2 


\section{METHODOLOGY}

In order to design a four notched band antenna, two aims are considered. First, designing an antenna capable of covering UWB bandwidth, and second creating notch structure in antenna to remove the interference caused by the bandwidth. To this end, a UWB antenna is designed and the addition of each of notches is discussed in the following sections.

\section{A. Designing a UWB Antenna}

The proposed UWB antenna is modified in three steps as shown in Fig. 2. In first step (Fig. 2a), a simple rectangular patch and a ground fed by a microstrip feed line are used. The results of each section are illustrated in Fig. 3. In first step, antenna can cover impedance bandwidth from 4.93 to 10.21 GHz. By modifying the ground plane (Fig. 2b) from a rectangular shape to a trapezoid shape and developing a conductor, where the microstrip feed line and patch meet, by a stepped triangular, the impedance bandwidth is expanded from 4.98 to $10.36 \mathrm{GHz}$. As observed in Fig3, the lower region of the antenna is not marked properly to work in UWB application. To improve this region, the distance between antenna patch and the ground should be increased. Therefore, the ground plane at the end of the ground should be eliminated with a rectangular shape. Finally, the antenna could cover 3.17 to $11 \mathrm{GHz}$ for UWB application.

\section{B. Discussion on Notches}

In this section, using a smith chart in order to survey the effects of each of notches, the study will discuss the role of notches. To this end, the use of UWB antenna impedance matching as the base of analysis curve is offered. In Fig. 4, four steps of developing the proposed antenna are presented. As seen in Fig. 4a, by etching a C-shape on feed line, there will be a notch on antenna bandwidth of 7.04 to $8.55 \mathrm{GHz}$. Regarding the obstacle made to the flow of input current, accumulated flow changes the capacitance effect on antenna from 7.04 to $8.55 \mathrm{GHz}$. In Fig. 4b, using the conventional approach, the researchers created a U-shaped slot on patch which leads to a change in inductance effect from 4.19 to 4.88 GHz. The possible reason for this issue is the strong current surrounding the notch. In the third step of antenna designing procedure, as displayed in Fig. 4c, two L-shape and a horizontal line slots change the real part of impedance and the third notch in antenna. The important feature distinguish the proposed antenna from other multiple notches, in addition to having four notches, is the type of the fourth notch.

In the fourth notch of the antenna, a C-shaped element which is connected to the patch with a metalized via hole leads to a filtering bandwidth from 5.55 to $5.96 \mathrm{GHz}$. In this notch, the metalized via hole prevents the spread of current in surface of the patch in filtering frequency by transferring the current from patch surface to $\mathrm{C}$-shaped structure under patch. Impedance matching and surface current of step four are shown in Fig. 4. 
Journal of Microwaves, Optoelectronics and Electromagnetic Applications, Vol. 16, No. 3, September 2017769 DOI: http://dx.doi.org/10.1590/2179-10742017v16i3915
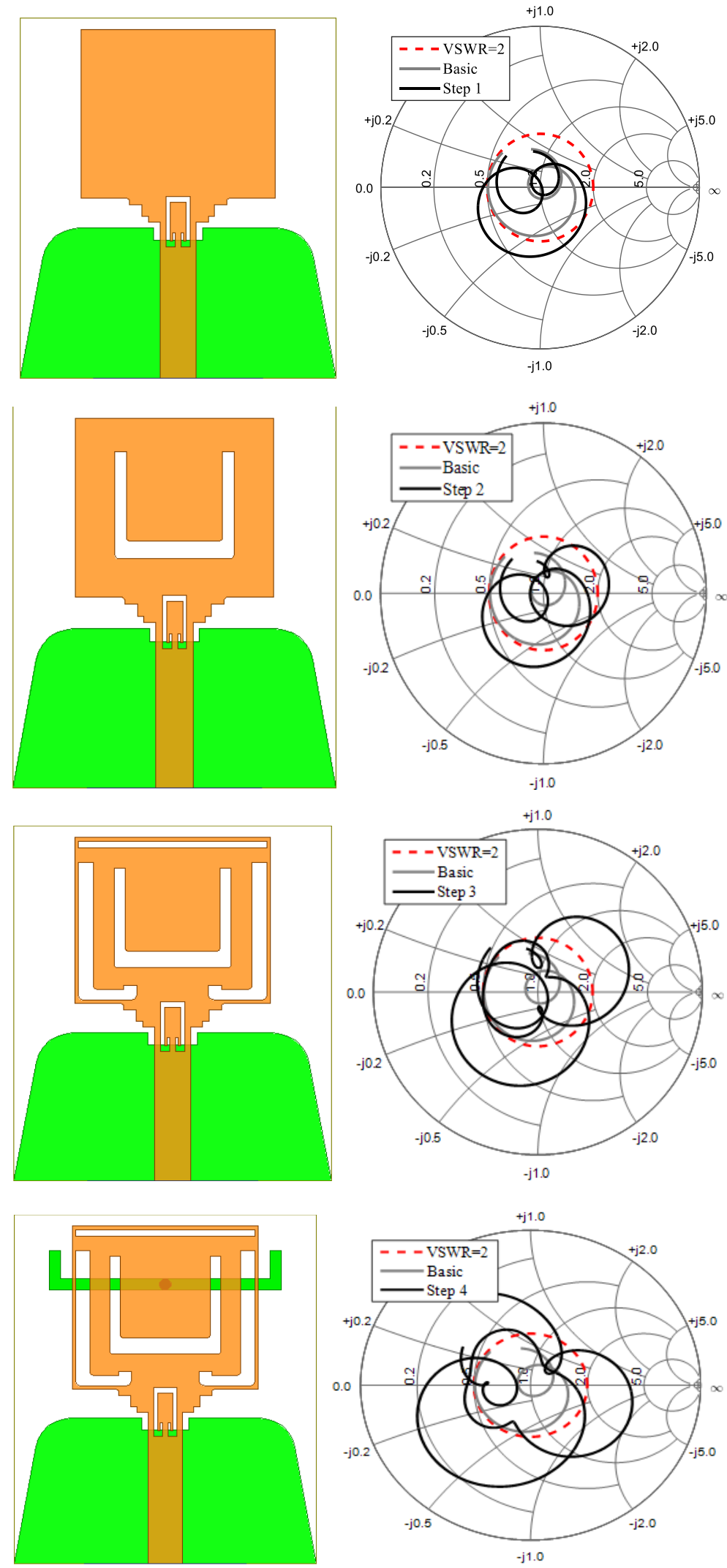
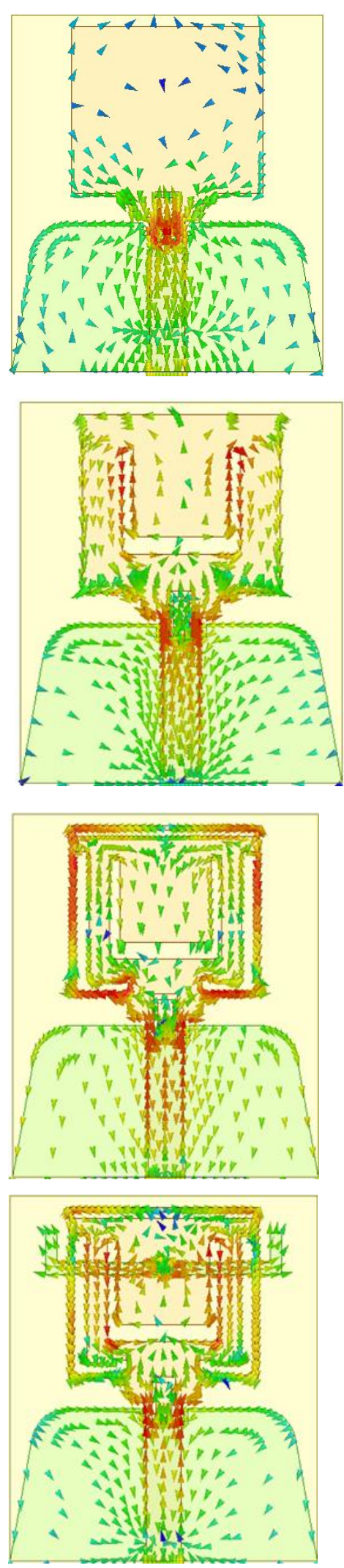

Fig. 4. The steps of designing, associated impedance matching curve for each of steps and surface current of corresponding with filtered band 


\section{EXAMINING THE FOURTH STEP}

All parameters of the antenna were optimized by using High Frequency Structure Simulator (Ansys HFSS ver.13). The fourth step of the antenna which plays a distinguishing role in antenna is discussed in this section. It should be noted that the $S_{11}$ of antenna at the presence or absence of metalized via hole is displayed in Fig. 5. As shown in Fig. 5, without using a metalized via hole, the antenna behaves like a triple notch antenna. This is due to the fact that the effective size of a non-planar structure without a metalized via hole is almost equal to those of notches that were created in step three of Fig. 4(c). By creating a metalized via hole, the effective size of the patch and that of the nonplanar C-shaped structure vary that cause fourth notch.

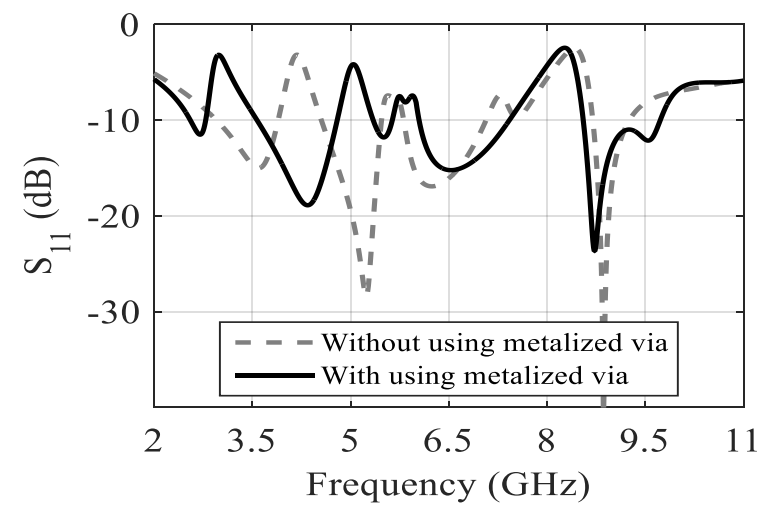

Fig. 5. Simulated $S_{11}$ at the presence or absence of metalized via hole
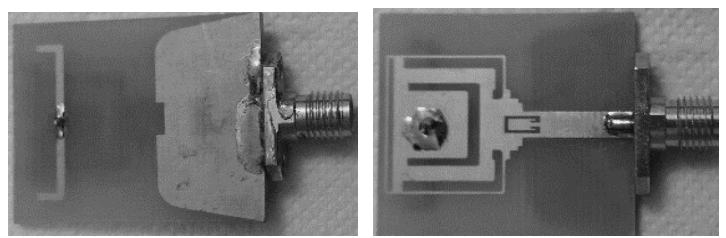

(a)

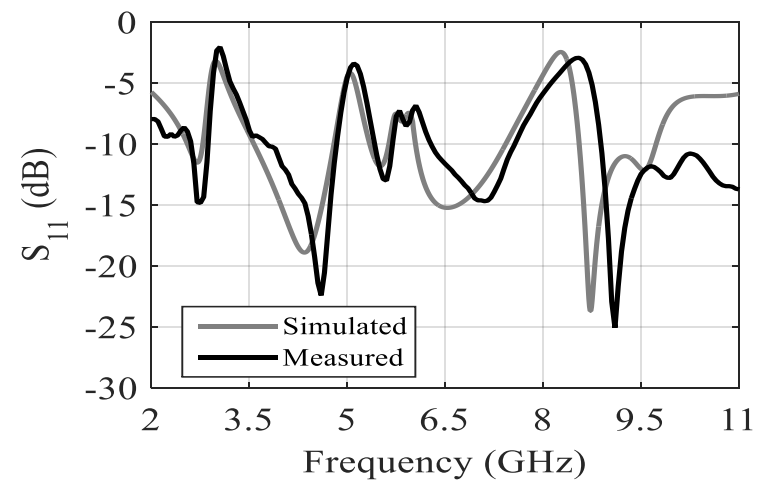

(b)

Fig. 6. (a) fabricated antenna (b) The comparison between simulated and measured $S_{11}$ of propose four notches antenna

\section{RESULTS AND DISCUSSION}

The proposed antenna was fabricated (Fig. 6a) and then measured by Agilent N5242A vector network analyzer. The comparison between simulated and measured S11 is shown in Fig. 6b. As proved by Fig. 6b, the antenna covered 2.55 to $11 \mathrm{GHz}$ with filtering band regions of (2.74-3.54GHz), 
Journal of Microwaves, Optoelectronics and Electromagnetic Applications, Vol. 16, No. 3, September 2017771 DOI: http://dx.doi.org/10.1590/2179-10742017v16i3915

(4.73-5.25GHz), (5.54-6.12GHz), and (7.6-9.1GHz). An acceptable matching was observed between simulated and measured results with little difference due to a fabrication error.

\section{E-plane}
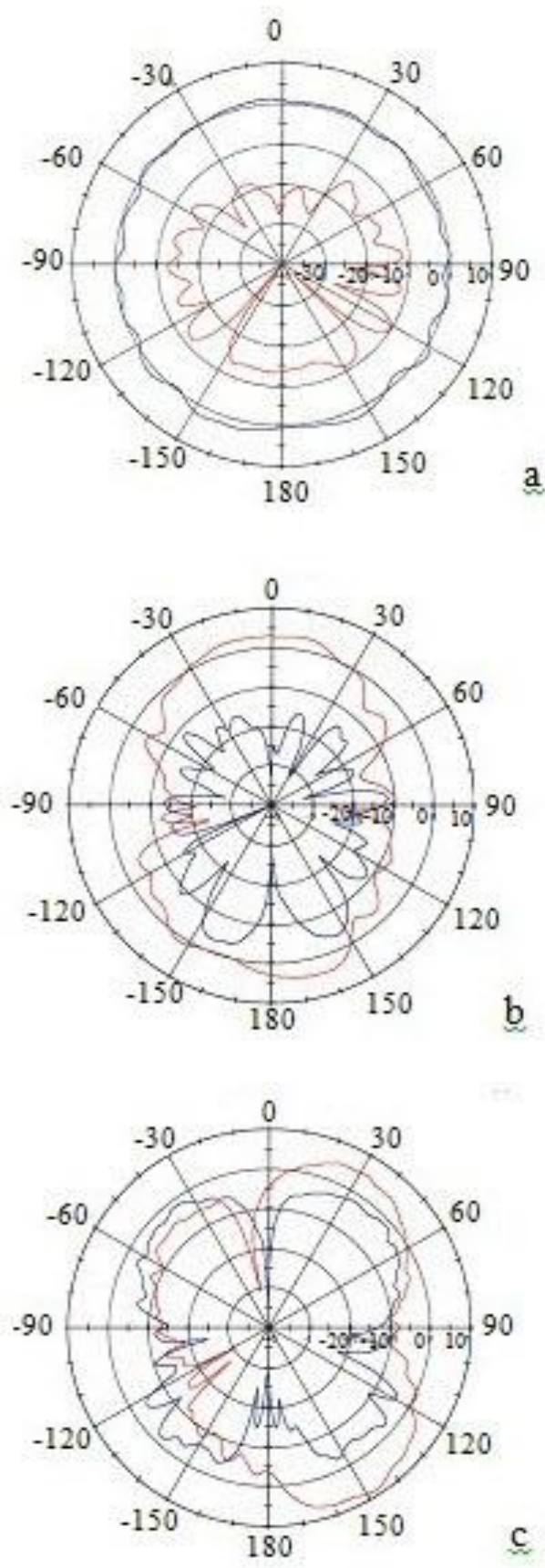

E-plane
H-plane
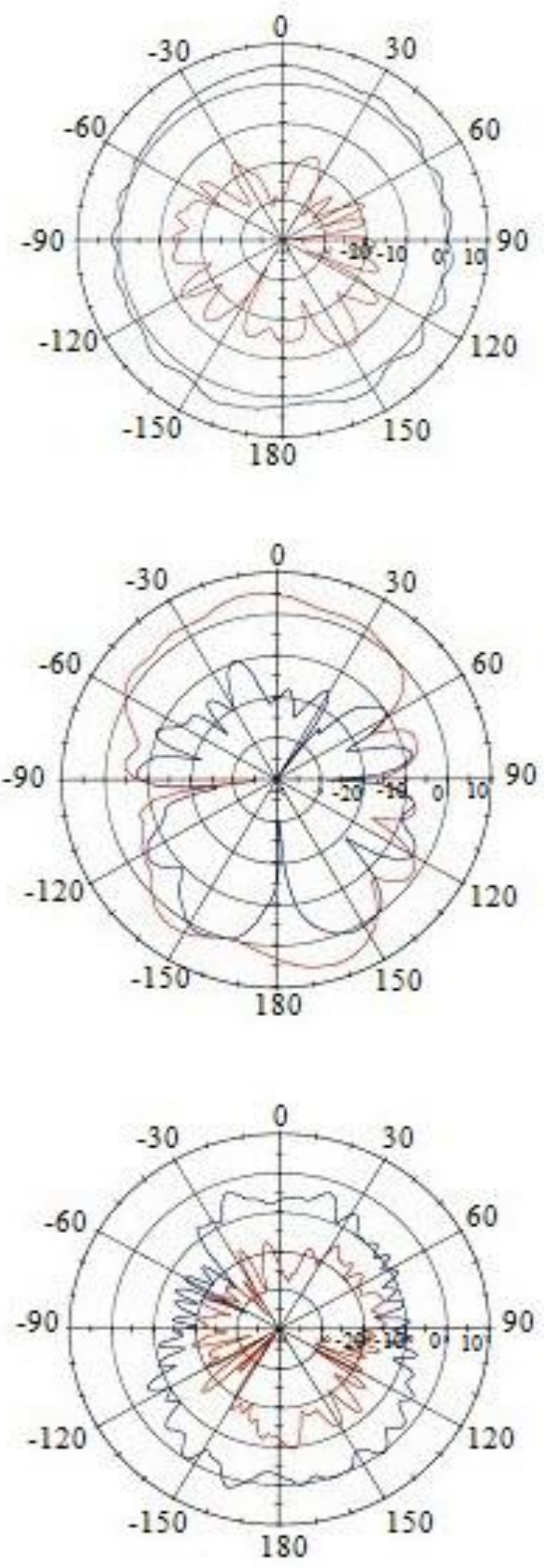

H-plane

Fig. 7. Radiation pattern at a) $2.6 \mathrm{GHz}$, b) $5 \mathrm{GHz}$, and c) $9.5 \mathrm{GHz}$. (in E-plane red color is Co polarization and blue is Crosspolarization and in H-plane red color is Cross-polarization and blue color is Co-polarization)

Fig.7 shows measured radiation pattern in H-plane (x-y plane) and E-plane (y-z plane) at 2.6, 5 and $9.5 \mathrm{GHz}$. It is easily approved that the radiation pattern of H-plane is nearly Omni-directional for all frequencies. The E- 
plane pattern is bidirectional in nature. The comparison between simulated and measured gains of the UWB antenna with four notched bands bands is shown in Fig. 8. The average gain of the proposed antenna is nearly constant, $3 \mathrm{dBi}$ in the entire UWB range. However, by the introduction of four notch bands at 3,5.3, 5.8 and $8.4 \mathrm{GHz}$ frequencies, the gain becomes negative which shows the good bandnotch performance of UWB antenna.

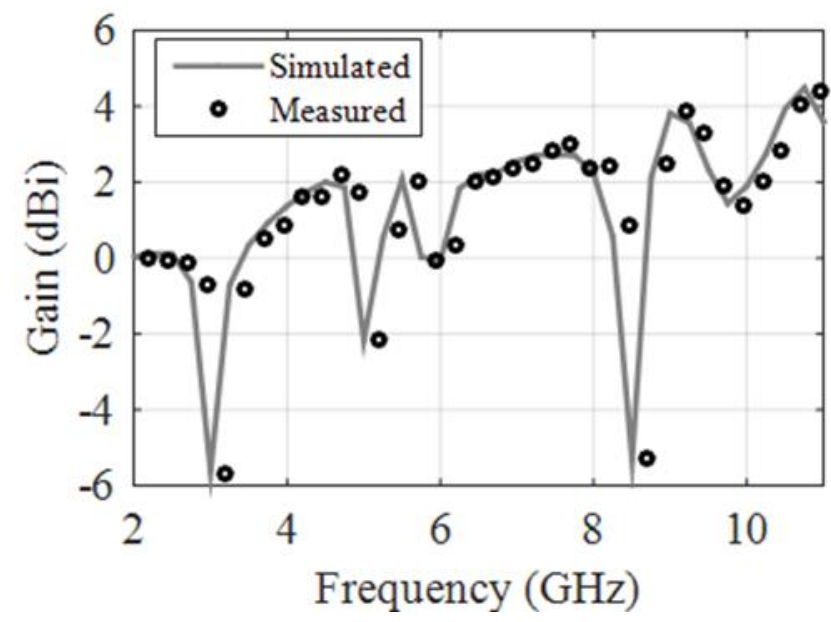

Fig. 8. Comparison results between simulated and measured gain of proposed antenna

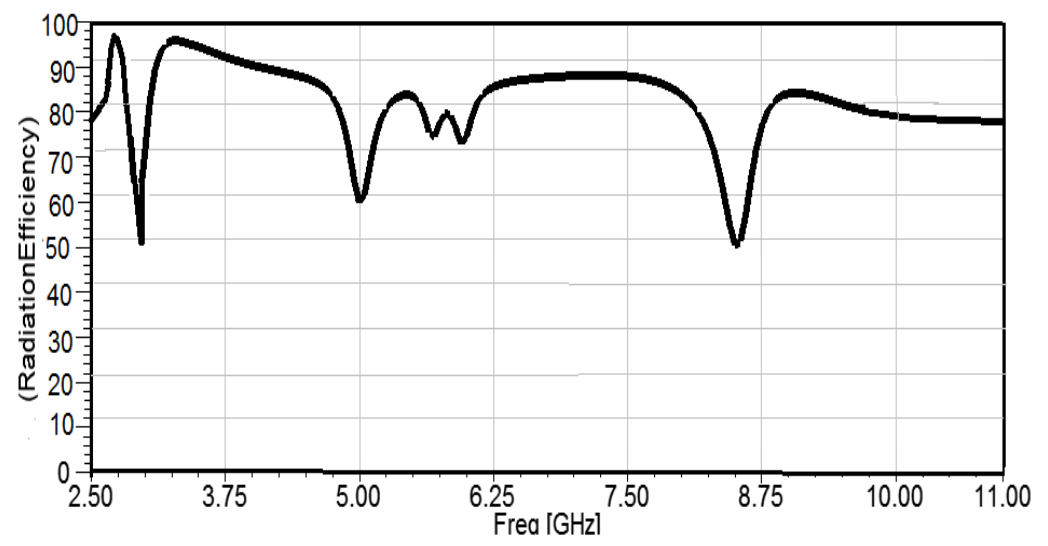

Fig. 9. Radiation efficiency of the proposed antenna

Fig. 9 presents the efficiency of the proposed antenna, which is approximately over 95\%. The efficiency of the antenna decreased consumedly at notch bands as shown here. Also at the notch frequencies, the antenna efficiency reduced to $50 \%$.

\section{THE AHP METHOD: A NEW METHOD TO COMPARE THE PERFORMANCE OF THE PROPOSED ANTENNA WITH THE PREVIOUSLY DISCUSSED ANTENNAS}

AHP is one of the most popular versatile decision making techniques that was developed by Thomas. El. Saaty in the 1970s. This decision making method is one of the techniques of Multi Attribute Decision Making «MADM» method. In this section, the researchers applied Analytic Hierarchy Process (AHP) to compare the proposed UWB antenna with previously designed antennas 
$(24,25,26, \& 27)$. The proposed antenna is compared with other 4 UWB antennas regarding three parameters of bandwidth, the number of notches, and overall size.

The characteristics of the mentioned antennas are summarized in Table 1. The Schematic structure of the Analytic Hierarchy Process is explained in 3 parts. The first part is the goal of the study. The other two parts are the substrates of the goal; in these sections, the antennas and the regarding characteristics are discussed. In the present study, comparing the effective factors for selecting an antenna with the capability to remove 4 bands, the researchers could be able to choose the most appropriate antenna.

The schematic structure of the AHP is shown in Fig. 10. Here "Selecting the best antenna structure" is pursued.

AHP is a simple method of comparison which helps avoid the complexity of other methods and make the right choice. For example, the aim of the present study was to design an antenna with a high bandwidth, small size, and high number of notches. Applying this method, one can easily choose the appropriate antenna from among several similar antennas designed previously equation for assessing the aforementioned antennas is introduced here:

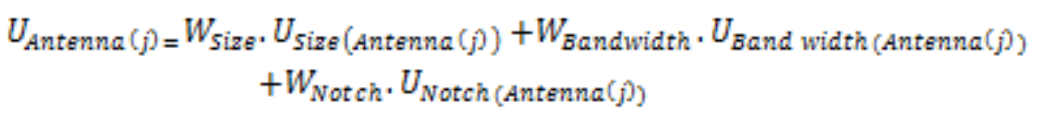

In the above equation, $W_{\text {Size }}, W_{\text {Bandwidth }}$, and $W_{\text {Noteh }}$ are the values given to size, bandwidth, and notch, respectively. The features of the proposed antenna such as size, bandwidth, and the number of notch bands, along with the 4 previously designed antennas are presented in Table 1. Implementing Expert choice software and employing AHP technique for comparing the 4 cases with different values presented in Table 2, one can recognize the superiority of each of the antennas. The comparison is presented in Table 3.

As can be seen from Figure 11, with regard to the first case, all the features had the same weight value and the proposed antenna was the best choice. In the second case, 'size' had the most weight value, thus the antenna number 25 was the best choice. With regard to the third and fourth cases, where 'bandwidth' and 'notch' had the highest weight values, respectively, compare to other features, the proposed antenna yielded better result. According to the above comparison and accurate results obtained from the study, it can be said that the proposed method is a great method for selecting the best antenna with regard to specific applications. 
Journal of Microwaves, Optoelectronics and Electromagnetic Applications, Vol. 16, No. 3, September 2017774 DOI: $\underline{\text { http://dx.doi.org/10.1590/2179-10742017v16i3915 }}$

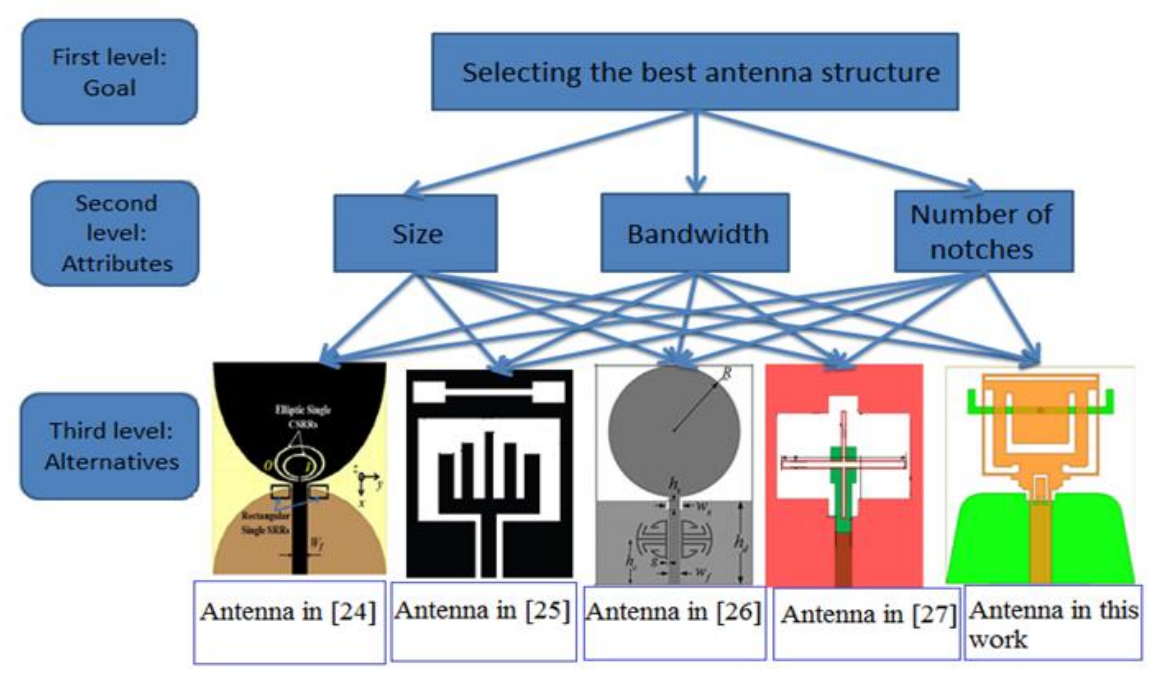

Fig. 10. Analytical Hierarchy Process (AHP) schematic for the antenna selection problem

Table 1. comparison of the proposed antenna size and simulated characteristics with other references. the impedance bandwidth is for a frequency range where VSWR $\leq 2$;

\begin{tabular}{c|cccc}
\hline \hline Ref. & Size $\left(\mathrm{mm}^{3}\right)$ & BW $(\mathrm{GHz})-\%$ & Substrate $\left(\varepsilon_{\mathrm{r}}\right)$ & Notch number \\
\hline$[24]$ & $35 \times 35 \times 1.6$ & $(2.8-11.8)-123.29 \%$ & $(4.4)$ & 3 \\
\hline$[25]$ & $21 \times 28 \times 1.6$ & $(2.8-11.3)-120.57 \%$ & $(2.65)$ & 3 \\
\hline$[26]$ & $36.6 \times 26.6 \times 1$ & $(2.5-10.9)-73.68 \%$ & $(4.4)$ & 3 \\
\hline$[27]$ & $35 \times 30 \times 1.5$ & $(3.1-10.5)-108.82 \%$ & $(2.65)$ & 3 \\
\hline This work & $26 \times 30 \times 1.6$ & $(2.55-11)-124.72 \%$ & $(4.4)$ & 4 \\
\hline \hline
\end{tabular}

Table 2.4 cases with different values for the various attributes

\begin{tabular}{c|ccc}
\hline \hline Cases & $\mathrm{W}_{\text {size }}$ & $\mathrm{W}_{\text {bandwidth }}$ & $\mathrm{W}_{\text {notches }}$ \\
\hline Case 1 & 0.3 & 0.3 & 0.3 \\
\hline Case 2 & 0.5 & 0.25 & 0.25 \\
\hline Case 3 & 0.25 & 0.5 & 0.25 \\
\hline Case 4 & 0.25 & 0.25 & 0.5 \\
\hline \hline
\end{tabular}

Table 3. Utility values of the antennas in four different cases for weight assignments

\begin{tabular}{c|ccccc}
\hline \hline Cases & This antenna & Antenna[24] & Antenna[25] & Antenna[26] & Antenna[27] \\
\hline Case 1 & 0.225 & 0.181 & 0.221 & 0.191 & 0.182 \\
\hline Case 2 & 0.219 & 0.169 & 0.232 & 0.204 & 0.176 \\
\hline Case 3 & 0.226 & 0.193 & 0.221 & 0.174 & 0.186 \\
\hline Case 4 & 0.231 & 0.183 & 0.213 & 0.190 & 0.183 \\
\hline \hline
\end{tabular}




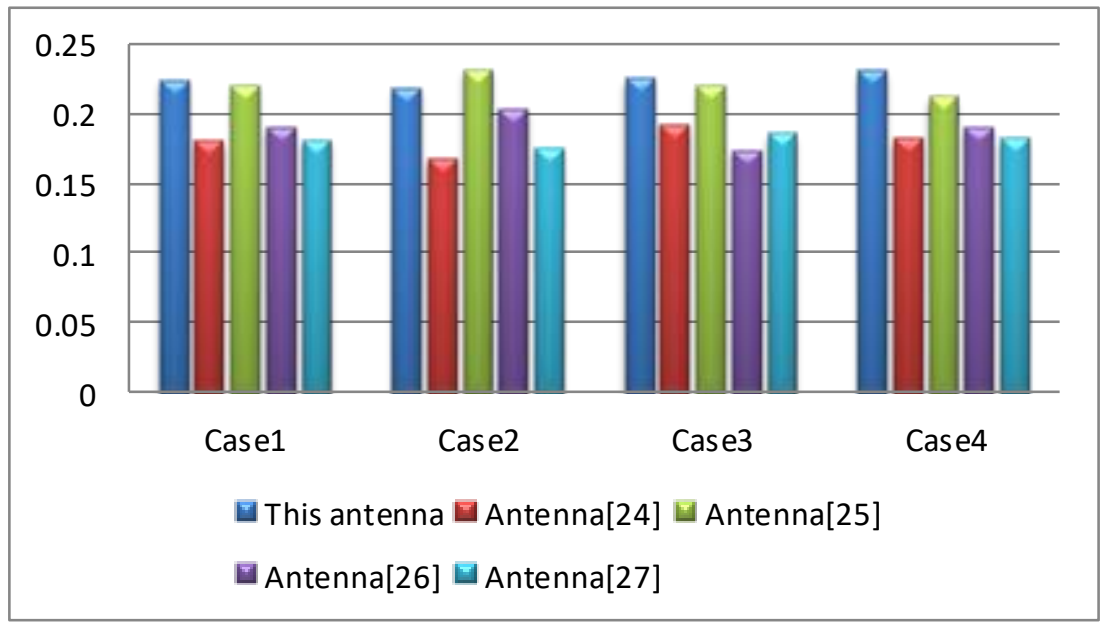

Fig.11. Utility values for the antennas in four different cases

\section{CONCLUSION}

In this study, a new UWB antenna is proposed with dimensions of $26 \times 30 \times 1.6 \mathrm{~mm}^{3}$ and the capability of filtering the disturbing frequency bands of WLAN, a part of C-Band, S-Band, and X-Band (satellite service bands as identified by the International Telecommunication Union (ITU)). This antenna is able to cover the broadband frequency from 2.55 to $11 \mathrm{GHz}$ for $\mathrm{VSWR}<2$. Also, the three main characteristics of this antenna are: 1) Wide bandwidth, 2) proper radiation performance, and 3) small size.

Moreover, a detailed comparison was done using Expert choice software and AHP technique. The results revealed that the proposed antenna is the best choice for the mentioned purpose. This technique provides a convenient and accurate assessment for users to make a right choice when selecting the required antenna for specific applications. The simulated and experimental results confirmed that the proposed antenna could be a good candidate for UWB applications.

\section{ACKNOWLEDGMENT}

The authors thank of the Islamic Azad University of Urmia, Iran, for allowing us to use the PNA-X network analyzer system (N5242A) for testing antenna in microwave laboratories.

\section{REFERENCES}

[1] Tang, Z.-j., Zhan, J. and Wu, X.-f, "Compact triple band-notched printed antenna with multi slots for UWB applications," Microwave And Optical Technology Letters, Vol. 57, pp. 2056-2060, 2015.

[2] Y. F. Weng, S. W. Cheung and T. I. Yuk, "Design of multiple band-notch using meander lines for compact ultrawide band antennas," IET Microwaves, Antennas \& Propagation, Vol. 6, pp. 908-914, June 72012.

[3] A. De Oliveira, M. Perotoni, S. Kofuji and J. Justo, "A Palm Tree Antipodal Vivaldi Antenna With Exponential Slot Edge for Improved Radiation Pattern", IEEE Antennas and Wireless Propagation Letters, vol. 14, pp. 1334-1337, 2015.

[4] Y. Cho, K. Kim, D. Choi, S. Lee and S. Park, "A Miniature UWB Planar Monopole Antenna With 5-GHz BandRejection Filter and the Time-Domain Characteristics", IEEE Transactions on Antennas and Propagation, vol. 54, no. 5, pp. 1453-1460, 2006.

[5] K. Shan, C.L. Ruan, and L. Peng, "Compact UWB antenna with band-notched characteristic using a coupling strip," International Symposium on Intelligent Signal Processing and Communication Systems, pp. 1-4, 2010.

[6] P. Gao, L. Xiong, and J.B. Dai, "Compact printed wide-slot UWB antenna with 3.5/5.5 GHz dual band-notched characteristics," IEEE Antennas Wireless Propag Lett, Vol 12, pp. 983-986, 2013.

[7] N. Mohammadian, M.N. Azarmanesh, and S. Soltani, "Compact ultrawideband slot antenna fed by coplanar waveguide and microstrip line with triple-band-notched frequency function," IET Microwave Antennas Propag, Vol 4, pp. 1811-1817, 2010.

[8] J.W. Wang, J.Y. Pan, and X.N. Ma, "A band-notched UWB antenna with L-Shaped slots and open-loop resonator," Proceedings of Applied Superconductivity and Electromagnetic Devices, Beijing, China, pp. 312-315, 2013. 
[9] R. Zaker, C. Ghobadi, and J. Nourinia, "Bandwidth enhancement of novel compact single and dual band-notched printed monopole antenna with a pair of L-shaped slots," IEEE Trans Antennas Propag, Vol 57, pp. 3978-3983, 2009.

[10] DE OLIVEIRA, Alexandre M. et al. "A palm tree antipodal Vivaldi antenna with exponential slot edge for improved radiation pattern," IEEE Antennas and Wireless Propagation Letters, v. 14, p. 1334-1337, 2015.

[11] S. Mohammadi, J. Nourinia, and C. Ghobadi," Compact CPW-fed rotated square- shaped patch slot antenna with band-notched function for UWB applications," Electronics Letter, Vol. 47, pp. 1307-1308, 2011.

[12] O. Nasser, O. Mohammad, and G. Noradin, "Dual band-notched small monopole antenna with novel W-shaped conductor backed-plane and novel T-shaped slot for UWB applications," IET Microw. Antennas Propag, Vol. 7, pp. 8-14, 2013.

[13] P Syam Sundar, Sarat K Kotamraju, B T P Madhav, M Sreehari, K Raghavendra Rao, L Prathyusha, Y Pravallika, "Parasitic Strip Loaded Dual Band Notch Circular Monopole Antenna with Defected Ground Structure," International Journal of Electrical and Computer Engineering (IJECE), Vol 6, pp. 1742-1750, 2016.

[14] Y. J. Cho, K. H. Kim, D. H. Choi, S. S. Lee, S. O. Park, A Miniature WB Planar monopole Antenna With 5-GHz Band-Rejection Filter and the Time-Domain Characteristics," IEEE Transaction Antennas and Propagation. Vol. 54 No. 5, May 2006.

[15] Ma, T.G., Wu, S.J, "Ultrawideband band-notched folded strip monopole antenna," IEEE Trans. Antennas Propag, Volume 55, pp. 2473-2479, September 2007.

[16] Kim, J., Cho, C.S., Lee, J.W, "5.2 GHz notched ultra-wideband antenna using slot type SRR", Electron. Lett, Vol 42 , No 6, pp. 315-316, March 2006.

[17] Arash Khalilzadeh, Adrian Eng-Choon Tan, Karumudi Rambabu, "Design of an integrated UWB antenna with dual band notch characteristics," International Journal of Electronics and communications, Vol 67, pp. 433-437, 2013.

[18] Weng, Y.F., Cheung, S.W., Yuk, T.I, "Triple band-notched UWB antenna using meandered ground stub,"Loughborough Antennas and Propagation Conf., Loughborough, pp. 341-344, November 2010.

[19] Ziyang Wang, Jinhai Liu, Yingzeng Yin, "Triple Band-Notched UWB Antenna using novel asymmetrical resonators," International Journal of Electronics and Communications, Vol 70, 2016.

[20] DS Ramkiran, B T P Madhav, Kankara Narasimha Reddy, Shaik Shabbeer, Priyanshi Jain,Saggurthi Sowmya, "Coplanar Wave Guide Fed Dual Band Notched MIMO Antenna," International Journal of Electrical and Computer Engineering (IJECE), Vol 6, pp. 1732-1741, 2016.

[21] Dong, Y.D., Hong, W., Kuai, Z.Q., Chen, J.X, "Analysis of planar ultrawideband antennas with on-ground slot bandnotched structures," IEEE Trans. Antennas Propag, Vol. 57, pp. 1886-1893, July 2009.

[22] Pancera, E., Modotto, D., Locatelli, A., Pigozzo, F.M., De Angelis, C, "Novel design of UWB antenna with bandnotch capability,"European Conf. on Wireless Technologies, pp. 48-50, December 2007.

[23] Lee, S.H., Baik, J.W., Kim, Y.S, "A coplanar waveguide fed monopole ultra- wideband antenna having band-notched frequency function by two folded- stripline," Microw. Opt. Technol. Lett, Volume 49, pp. 2747-2750, August 2007.

[24] Sarkar, D.; Srivastava, K.V.; Saurav, K, "A Compact Microstrip-Fed Triple Band- Notched UWB Monopole Antenna," Antennas and Wireless Propagation Letters, IEEE, Vol.13, pp.396-399, 2014.

[25] Badamchi, Z. and Zehforoosh, Y. (2015), Switchable single/dual band filtering UWB antenna using parasitic element and T-shaped stub wave cancellers. Microw. Opt. Technol. Lett., 57: 2946-2950.

[26] M. Sefidi, Y. Zehforoosh and S. Moradi, "A small CPW-fed UWB antenna with dual band-notched charectrestics using two stepped impedance resonators", Microwave and Optical Technology Letters, vol. 58, no. 2, pp. 464-467, 2015.

[27] N. Ojaroudi A. Musavand, Y. Zehforoosh and H. Ojaroudi, “A Compact UWB Slot Antenna with Reconfigurable Band-Notched Function for Multimode Applications," Applied Computational Electromagnetics Society (ACES) Journal, vol. 31, no. 1, pp. 14-18, Jan. 2016.

[28] Sefidi, M., Zehforoosh, Y. and Moradi, S. (2015), A novel CPW-fed antenna with dual band-notched charectrestics for UWB applications. Microw. Opt. Technol. Lett., 57: 2391-2394.

[29] Ch. Ghobadi , M. Majidzadeh, " Multi Attribute Analysis of a Novel Compact UWB Antenna with Via-fed Elements for Dual Band Notch Function," International Journal of Engineering, Vol. 27, pp. 1565-1572, October 2014. 